\title{
The Rice Effect: Sugarcane Production in Florida Following Rice ${ }^{1}$
}

José Alvarez and George H. Snyder ${ }^{2}$

\section{Introduction}

In the Everglades Agricultural Area (EAA), south of Lake Okeechobee in Florida, approximately 445,000 acres (180,000 hectares) of land are devoted to sugarcane production. Sugarcane is generally harvested from October through April, and replanted from August through January, approximately every four years. Thus, more than 50,000 acres $(20,000$ hectares) of land, some flooded, are commonly idle from five to twelve months during the spring and summer.

After being used as a cover crop for many years, rice was harvested for grain in the EAA for the first time in 1977, after it was demonstrated that rice could be incorporated into the sugarcane production cycle during the fallow period (Alvarez, et al., 1978). Since sugarcane is the principal crop in the rice-sugarcane rotation, researchers at the University of Florida's Everglades Research and Education Center (EREC) conducted experiments to determine the effect of rice production upon the sugarcane plant crop that followed the rice crop. This document summarizes two experiments. The first analysis was based on each producer's records (Alvarez and Snyder, 1984). The second was an experiment in commercial fields (Snyder, et al., 1986).

\section{The First Experiment: Producer's Records}

In the absence of data from controlled experiments in the EAA, reliable information was obtained directly from the field records of four producers from 1977 through 1980. All fields were approximately 40 acres (16 hectares) and were scattered throughout the EAA. All soils were Histosols containing over 70 percent organic matter.

\section{Method of Analysis}

The rice effect was evaluated as follows: sugarcane plant crop yield data were collected from 82 fields in which a rice crop immediately preceded a sugarcane crop (termed rice fields). Similar data were also collected from nearby fields that were fallowed during the summer prior to the next sugarcane planting (fallow fields). Since rice growers generally plant on more than half their available

1. This is EDIS document FE474, a publication of the Department of Food and Resource Economics, Florida Cooperative Extension Service, UF/IFAS, University of Florida, Gainesville, FL. Published May 2004. This publication is also part of the Florida Sugarcane Handbook, an electronic publication of the Department of Agronomy, University of Florida, Gainesville, FL. For more information, you may contact the editor of the Sugarcane Handbook, Dr. R.A. Gilbert (ragilbert@ifas.ufl.edu), Everglades Research and Education Center, University of Florida, Belle Glade, FL 33430. Please visit the EDIS website at http://edis.ifas.ufl.edu.

2. José Alvarez, Professor, Department of Food and Resource Economics, and George H. Snyder, Distinguished Professor, Department of Soil and Water Science, Everglades Research and Education Center, Belle Glade, FL, Florida Cooperative Extension Service, UF/IFAS, University of Florida.

The Institute of Food and Agricultural Sciences is an equal opportunity/affirmative action employer authorized to provide research, educational information and other services only to individuals and institutions that function without regard to race, color, sex, age, handicap, or national origin. For information on obtaining other extension publications, contact your county Cooperative Extension Service office. Florida Cooperative Extension Service/Institute of Food and Agricultural Sciences/University of Florida/Christine Taylor Waddill, Dean. 
fields, more observations were available from rice fields than from fallow fields. In some instances, due to their location in the middle of a large group of rice fields, fewer fallow fields were necessary for comparison purposes. It was not always possible to obtain fallow field data for the same sugarcane variety that was used in the planting that followed rice. Therefore, in addition to the yield data (gross tons and percentage of sucrose in normal juice), information was obtained on sugarcane variety, producing firm, planting and harvesting dates, and method of harvesting. Thus it was possible to derive equations to estimate the average sugarcane plant crop yield for rice fields and for fallow fields. The difference between these yields was termed the rice culture effect.

Implicit in this analysis is the assumption that both sets of fields (which had an identical cropping sequence in the previous cycle; that is, fallow/sugarcane) would have produced approximately equal sugarcane yields in the absence of rice production in one set. To check the validity of this assumption, the plant crop data from the previous cycle in the same fields were collected and analyzed using regression analysis.

\section{Results and Discussion}

The yield comparisons between the fallow fields and the rice fields for the sugarcane plant crop of the previous cycle supported the hypothesis that approximately equivalent fields were chosen to estimate the rice culture effect. No significant differences were found in the equations for percentage of sucrose in normal juice $(\mathrm{P}>0.91)$ and tons of sugar $(P>0.65)$. Since the fallow fields actually had higher production (1.09 net tons per acre) than the rice fields, any positive rice effect would be conservative with respect to net tons.

The regression results of the rice culture effect show that in general all three models are statistically sound (Alvarez and Snyder, 1984, p. 318). The coefficients of the rice culture variable in the three models show a positive sign and a high statistical significance, indicating a beneficial effect of rice upon subsequent yields of sugarcane. All three intercepts were significant at the $\mathrm{P}=0.01$ level. There was a significant variety of rice culture interaction.
The sign of the interaction term was the same for all varieties in the three models, and only the magnitude of the coefficients varied with variety. Therefore, a mean value across varieties is used in all subsequent calculations. The adjusted coefficients of determination $\left(\mathrm{R}^{2}\right)$ were very good for these types of cross-section data.

The rice culture effect was substantial, with increases of 7.9 net tons of millable sugarcane per acre, 0.73 percent sucrose in normal juice per net ton of sugarcane, and 0.93 tons of sugar per acre.

\section{The Second Experiment: Commercial Fields}

The second experiment was conducted on the Big B Farm property in the central region of the EAA during the1983 season (Snyder, et al., 1986).

\section{Method of Analysis}

Rice was produced in three fields at Location 1, in four fields at Location 2, and in eight fields at Location 3. An equal number of fallow fields were selected in Locations 1 and 3 on the basis of having been planted with the same varieties of sugarcane, on approximately the same dates, as were used in the rice fields. At Location 2, five fields were selected for comparison with the rice fields. The fields without rice production (termed check fields) were not flooded during the summer, whereas the rice fields were flooded for 150 days, for both the plant and ratoon crops, as part of the normal production system. Most fields were approximately 35 acres in size; the exception was the check fields at Location 3, which averaged 23 acres. Variety CP 72-1210 was planted at Location 1, and variety CP 70-1133 was planted at Locations 2 and 3.

\section{Results and Discussion}

Cropping with rice prior to planting substantially increased all measurements of production in the sugarcane plant crop at all locations, except for gross tons of sugarcane at Location 3. Although averages for quality factors (Brix, purity, sucrose, and $96^{\circ}$ yield) at Location 1 were numerically greater in the rice fields as compared to the check fields, there were no significant differences between the two field types 
at this location. Standard tons and recoverable sugar per acre (RSPA) were significantly greater for the rice fields at all three locations.

The average increase in gross tons was only 8.9 percent (3.84 gross tons per acre), whereas the average increase in net standard tons (net tons adjusted for sugar content of the sugarcane) was 27.8 percent (11.95 standard tons per acre). This difference occurred because, on average, using rice culture prior to sugarcane increased Brix by 8.0 percent and purity by 5.6 percent, which resulted in an increase in sucrose of 14.3 percent. RSPA averaged 1.0 ton per acre greater in the rice fields. Quality factors, such as Brix and purity, were particularly increased by the rice cultures at Locations 2 and 3 .

Sugarcane at these latter locations was harvested after severe freezes on January 6 and 22, 1985.

\section{Economic Implications: Measuring the Rice Effect}

There are two potential economic benefits to sugarcane growers from a rice-sugarcane rotation instead of fallowing in the short run. The first benefit is the direct return from the rice crop to the grower and those servicing the industry. The second benefit is the returns from the extra yield in the subsequent sugarcane crop. In the long run, this is a soil conservation practice, which results in more years of farming, because it slows down the oxidation of the organic soils.

The economic benefits, in terms of total net returns, can be calculated using the $\mathrm{NR}=(\mathrm{P} \times \mathrm{SRE})$ (HC x GRE) formula, where $N R$ equals total net returns; $P$ equals the price per pound of sugar; $S R E$ is the rice culture effect in terms of pounds of sugar per acre; $H C$ represents the extra harvesting, loading, and hauling costs per gross ton of sugarcane; and GRE is the rice culture effect expressed in gross tons of sugarcane per acre.

\section{The First Experiment}

The rice culture effect in the first experiment was estimated at 0.93 ton of sugar per acre. Harvesting, loading, and hauling costs for the 1983-84 season were $\$ 11$ per gross ton of sugarcane. The average season price of sugar was around $\$ 0.20$ per pound,
New York spot price, with $\$ 0.126$ going to the grower, reflecting the 63 percent share accruing to the producer of independent sugarcane. In terms of gross tons, assuming a three percent trash content, the rice culture effect was 8.14 gross tons per acre. Therefore, the rice effect equals a total net return of $\$ 145$ per acre $[(\$ 0.126 \times 1,860 \mathrm{lbs})$ - ( $\$ 11 \times 8.14$ gross tons $)]$. Extra returns also accrue to the processors grinding the sugarcane and to both growers and processors from the additional molasses produced.

\section{The Second Experiment}

The rice effect was estimated at one ton of sugar per acre. Harvesting, loading, and hauling costs for the 1984-85 season were $\$ 12$ per gross ton of sugarcane. The average season price of sugar was around $\$ 0.21$ per pound, with $\$ 0.1323$ going to the grower. In terms of gross tons, the rice culture effect was 8.6 tons per acre. Therefore, the rice effect equals a total net revenue of $\$ 161$ per acre $(\$ 0.1323$ x 2000 lbs) - (\$12 x 8.6 gross tons), excluding extra revenues from molasses.

\section{Conclusions and Implications}

The existence of a rice effect increasing both biomass and sucrose yields in the subsequent sugarcane plant crop in a rice-sugarcane rotation was established in the first experiment and confirmed in the second experiment.

Neither study provided any conclusive evidence as to the reason for the rice effect. A common factor in both experiments is that the summer fallow fields were not flooded, as opposed to the rice fields, which were flooded for an extensive period. Since the early times of rice production as a cover crop in the EAA, flooding has been shown to control a variety of plant pests such as soil-borne diseases, insects, and nematodes (Greene, 1953; Stoner and Moore, 1953; Thames and Stoner, 1953; Genung, 1970). However, the question of whether the rice effect is due solely to the extensive flooding associated with the crop was not resolved. First using a rice crop to recycle nutrients that might otherwise be leached from the soil by heavy summer rains could benefit the sugarcane crop that follows (Yadav and Singh, 1987, p. 600). Improvements in soil tilth, soil aeration, water infiltration and drainage following flooding and 
stubble incorporation, and better water table control associated with the use of laser leveling may also have contributed to the higher sugarcane yields.

There is one important implication derived from these results. Substantial average yield increases can be obtained by simply growing rice before replanting sugarcane fields. The actual magnitude of the rice culture effect for individual producers, as shown in both experiments, will depend upon a variety of factors. However, the unveiling of the existence of the rice effect in the EAA, later confirmed with field experiments on sandy loam soils in India (Yadav and Singh, 1987), could be of major economic importance to the sugarcane industry in south Florida and other areas of the world where rice can be grown in rotation with sugarcane.

\section{References}

Alvarez, Jose, and George H. Snyder. 1984. Effect of Prior Rice Culture on Sugarcane Yields in Florida. Field Crops Research 9:315-321.

Alvarez, Jose, Gerald Kidder, and George H. Snyder. 1978. The Economic Potential for Growing Rice and Sugarcane in Rotation in the Everglades. Proceedings of the Soil and Crop Science Society of Florida 38:12-15.

Genung, W.G. 1970. Flooding Experiments for Control of Wireworms Attacking Vegetable Crops in the Everglades. Florida Entomologist 53:55-63.

Greene, V.E., Jr. 1953. Rice Growing is Added to Everglades Agriculture. Crop Soils 6:14.

Snyder, G.H., R.H. Caruthers, J. Alvarez, and D.B. Jones. 1986. Sugarcane Production in the Everglades Following Rice. Journal of the American Society of Sugar Cane Technologists 6:50-55.

Stoner, W.N., and W.D. Moore. 1953. Lowland Rice Farming: A Possible Control for Sclerotina sclerotiorum in the Everglades. Plant Disease Reporter 37:181-186.

Thames, W.H., Jr. and W.N. Stoner. 1953. A Preliminary Trial of Lowland Rice Culture in Rotation with Vegetable Crops as a Means of
Reducing Root-knot Nematode Infestations in the Everglades. Plant Disease Reporter 37:187-192.

Yadav, D.V., and R.D. Singh. 1987. Effect on Yield and Juice Quality of Sugarcane Following Rice. Journal of Agricultural Sciences 109:599-600. 